\title{
Philadelphia-Positive B-Acute Lymphoblastic Leukemia: Does it Differ from Philadelphia-Negative One in Egyptian Populations?
}

\author{
Raafat Abdel-MALEK ${ }^{1}$, Somaya El-DEEB ${ }^{3}$, Hebatallah KASSEM ${ }^{2}$, \\ Fatma Abdel NASSER ${ }^{4}$, Neemat KASSEM ${ }^{2}$ \\ ${ }^{1}$ Cairo University, Faculty of Medicine, Kasr Al-Ainy Centre of Clinical Oncology \& Nuclear Medicine, Department of Clinical \\ Oncology, Cairo \\ ${ }^{2}$ Cairo University, Faculty of Medicine, Kasr Al-Ainy Centre of Clinical Oncology \& Nuclear Medicine, Department of Clinical \\ and Chemical Pathology, Cairo \\ ${ }^{3}$ Cairo University, Faculty of Science, Department of Immunology, Cairo \\ ${ }^{4}$ Cairo Oncology Center, Giza, EGYPT
}

\section{Dear Editor,}

In Egypt, the annual incidence of ALL is approximately four cases per 100000 children per year in the National Cancer Institute (NCI) Cairo University. ALL constitute $30 \%$ of all pediatric malignancies and $70 \%$ of pediatric leukemias. Cases show a male to female ratio of 2.3:1. The 2-10 years age group constitutes $68.5 \% .^{1}$ Approximately one-fourth of adult B-ALL expresses the oncogenic protein BCR-ABL1 that reflects a balanced reciprocal translocation between the long arms of chromosome 9 and 22 [t $(9 ; 22)(\mathrm{q} 34 ; \mathrm{q} 11)]$ involving the BCR and ABL genes. At present, detection of $\mathrm{BCR} / \mathrm{ABL}$ gene rearrangement is mandatory in B-ALL patients at diagnosis for prognostic stratification and treatment decision. ${ }^{2}$ Significant advances in treatment of $\mathrm{Ph}$-positive ALL have been made since the discovery of Imatinib which is a selective ABL tyrosine kinase inhibitor. Whereas the outcome with standard chemotherapy was previously poor, incorporation of Imatinib into treatment protocol has improved survival. ${ }^{3}$ Little evidence exists regarding the prevalence, clinical outcomes and molecular response of adult patients with $\mathrm{Ph}+$ versus $\mathrm{Ph}-\mathrm{B}-\mathrm{ALL}$ in our country. The aim of our study was to explore the presence of minor BCR-ABL (P190) gene in Egyptian B-ALL patients and correlate it with treatment outcome. Quantitative assessment of minor BCR-ABL gene expression was performed by qRT-PCR in 48 Egyptian B-ALL patients. All patients received classic ALL treatment in addition to TKI (Imatinib) in the minor BCR-ABL +ve patients. Among 48 patients of newly diagnosed B-Acute lymphoblastic leukemia, $21 \%$ of all patients possess $\mathrm{Ph}$ chromosome. Patients presenting with $\mathrm{Ph}+\mathrm{ve}$ ALL differed from those with Ph-ve ALL at some aspects as shown in Table 1a and 1b, firstly regarding the clinical data, the present study showed that median age is slightly higher; also the most presenting symptoms in $\mathrm{Ph}+\mathrm{ve}$ patients were easy fatigability and fever while bleeding, hepatomegaly and seplenomegaly were only $10 \%$. These findings were different from $\mathrm{Ph}$-ve patients although the difference was sometimes not significant. Our data compared to study from Pakistan and Singapore showed similarity regarding incidence, age and presentation. ${ }^{4-5} \mathrm{Re}-$ garding laboratory data, many studies including ours showed that $\mathrm{Ph}+\mathrm{ve}$ is associated with higher initial leukocyte counts and more blasts in the peripheral blood and bone marrow. ${ }^{4-5}$ In respect of immunophenotyping, similar to western data, ${ }^{6}$ the present study showed that CD19, CD22 and CD79a \% were higher in the $\mathrm{Ph}+\mathrm{ve}$, while data from Asian study reported that CD10 expression had significant difference. ${ }^{7}$

Regarding the treatment outcome as shown in Figure 1 and 2, the disease free survival was significantly higher among $\mathrm{Ph}+\mathrm{ve}$ patients than $\mathrm{Ph}$-ve patients $(\mathrm{p}=$ 0.049). This finding compared to older studies prior to use of Imatinib in Ph+ ALL showed that $\mathrm{Ph}+\mathrm{pa}-$ tients had poorer outcome..$^{7-9}$ 
International Journal of Hematology and Oncology

Table 1a. Clinicopathological parameters according to Ph status

\begin{tabular}{|c|c|c|c|c|c|}
\hline & \multicolumn{2}{|c|}{$P H+V E(n=10)$} & \multicolumn{2}{|c|}{ PH -VE $(n=38)$} & \multirow[t]{2}{*}{ P value } \\
\hline & $\mathbf{N}$ & $\%$ & $\mathbf{N}$ & $\%$ & \\
\hline \multicolumn{6}{|l|}{ Sex } \\
\hline Male & 4 & 40.0 & 25 & 65.8 & 0.164 \\
\hline Female & 6 & 60.0 & 13 & 34.2 & \\
\hline \multicolumn{6}{|c|}{ Easy fatigability } \\
\hline Yes & 7 & 70.0 & 15 & 39.5 & 0.152 \\
\hline No & 3 & 30.0 & 23 & 60.5 & \\
\hline \multicolumn{6}{|l|}{ Fever } \\
\hline Yes & 7 & 70.0 & 20 & 52.6 & 0.478 \\
\hline No & 3 & 30.0 & 18 & 47.4 & \\
\hline \multicolumn{6}{|c|}{ Bleeding tendency } \\
\hline Yes & 4 & 40.0 & 9 & 23.7 & 0.425 \\
\hline No & 6 & 60.0 & 29 & 76.3 & \\
\hline \multicolumn{6}{|c|}{ Hepatomegaly } \\
\hline Yes & 1 & 10.0 & 9 & 23.7 & 0.664 \\
\hline No & 9 & 90.0 & 29 & 76.3 & \\
\hline \multicolumn{6}{|c|}{ Splenomegaly } \\
\hline Yes & 1 & 10.0 & 14 & 36.8 & 0.140 \\
\hline No & 9 & 90.0 & 24 & 63.2 & \\
\hline \multicolumn{6}{|c|}{ Lymphadenopathy } \\
\hline Yes & 3 & 30.0 & 15 & 39.5 & 0.722 \\
\hline No & 7 & 70.0 & 23 & 60.5 & \\
\hline
\end{tabular}

Table 1b. Clinicopathological parameters according to Ph status

\begin{tabular}{|c|c|c|c|}
\hline & $P H+V E(n=10)$ & PH -VE $(n=38)$ & $P$ value \\
\hline \multicolumn{4}{|l|}{ Age (years) } \\
\hline Mean \pm SD & $37.9 \pm 12.0$ & $31.2 \pm 13.5$ & 0.169 \\
\hline Median & 42.5 & 26.0 & \\
\hline IQR & $26.0-46.0$ & $20.0-43.0$ & \\
\hline \multicolumn{4}{|l|}{$\operatorname{TLC}\left(x 10^{3} / \mathrm{cm}^{3}\right)$} \\
\hline Mean \pm SD & $58.8 \pm 72.8$ & $41.0 \pm 52.5$ & 0.203 \\
\hline Median & 30.0 & 20.1 & \\
\hline IQR & $19.8-53.1$ & $2.5-72.9$ & \\
\hline \multicolumn{4}{|l|}{$\mathrm{Hb}(\mathrm{g} / \mathrm{dL})$} \\
\hline Mean $\pm S D$ & $7.9 \pm 1.8$ & $8.5 \pm 2.1$ & 0.458 \\
\hline Median & 8.3 & 8.6 & \\
\hline IQR & $7.2-9.0$ & $7.3-10.0$ & \\
\hline \multicolumn{4}{|l|}{ PLTs $\left(\times 10^{3} / \mathrm{cm}^{3}\right)$} \\
\hline Mean $\pm \mathrm{SD}$ & $55.2 \pm 27.3$ & $58.0 \pm 47.6$ & 0.611 \\
\hline Median & 55.0 & 41.0 & \\
\hline IQR & $29.0-80.0$ & $20.0-86.0$ & \\
\hline \multicolumn{4}{|l|}{ PB blasts \% } \\
\hline Mean \pm SD & $62.1 \pm 22.8$ & $64.1 \pm 26.6$ & 0.816 \\
\hline Median & 57.0 & 70.5 & \\
\hline IQR & $43.0-90.0$ & $45.0-89.0$ & \\
\hline \multicolumn{4}{|c|}{ Bone marrow aspirate (BM blasts \%) } \\
\hline Mean \pm SD & $94.7 \pm 3.7$ & $82.8 \pm 23.5$ & 0.483 \\
\hline Median & 95.0 & 95.0 & \\
\hline IQR & 90.0 - 99.0 & $76.0-99.0$ & \\
\hline \multicolumn{4}{|l|}{ CD 19} \\
\hline Mean \pm SD & $83.6 \pm 17.7$ & $80.3 \pm 15.6$ & 0.341 \\
\hline Median & 91.2 & 84.4 & \\
\hline IQR & 70.0 - 96.0 & 72.0 - 93.0 & \\
\hline \multicolumn{4}{|l|}{ CD 22} \\
\hline Mean \pm SD & $67.5 \pm 15.8$ & $61.8 \pm 20.8$ & 0.431 \\
\hline Median & 68.5 & 62.5 & \\
\hline \multirow{2}{*}{\multicolumn{4}{|c|}{ CD 79a }} \\
\hline & & & \\
\hline Mean \pm SD & $71.6 \pm 27.1$ & $68.1 \pm 19.2$ & 0.509 \\
\hline Median & 77.0 & 68.2 & \\
\hline IQR & $62.0-94.4$ & $54.0-84.0$ & \\
\hline \multicolumn{4}{|l|}{ CD 10} \\
\hline Mean \pm SD & $54.0 \pm 33.1$ & $60.6 \pm 29.6$ & 0.594 \\
\hline Median & 55.0 & 64.0 & \\
\hline IQR & $18.0-88.0$ & $32.0-90.0$ & \\
\hline
\end{tabular}




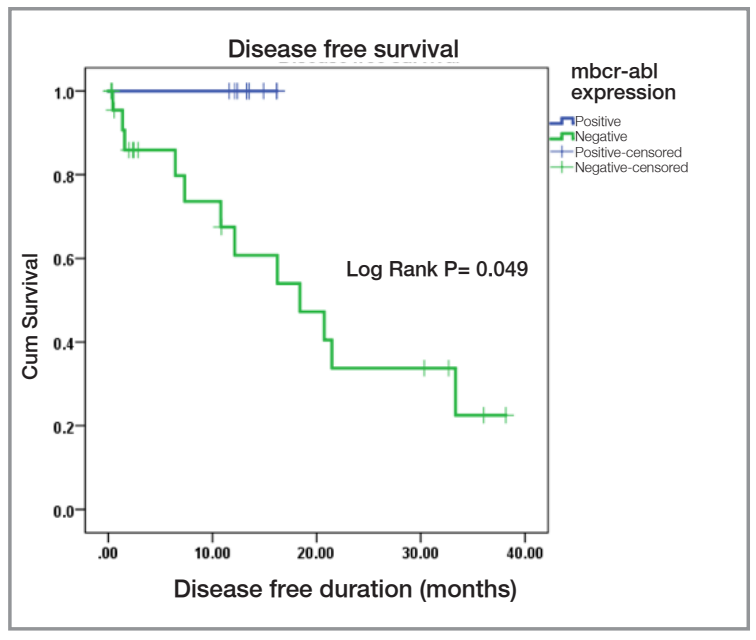

Figure 1. Disease Free Survival according to Ph chromosome status.

Concerning Molecular response (MR), in the present study after receiving chemotherapy accompanied with Imatinib, minor BCR-ABL fusion gene was expressed in mRNA of patient leukocyte (Mean $\pm \mathrm{SD}=0.006 \pm 0.006$ ), with a $3 \log$ reduction from baseline ratio. This is in accordance with the results previously reported that when Imatinib is added to induction therapy, minor BCR-ABL, mRNA was reduced at least 1 log from baseline after the first induction therapy. In conclusion The TKIs have significantly improved outcomes for adult patients with Ph-positive ALL, with the use of imatinib in combination with intensive chemotherapy early in the treatment course, and continuing through consolidation and maintenance considered as the current standard of care. Over the coming years, the treatment of adult ALL will certainly change from disease-type to molecular-target type and from risk-stratified treatment schedules to more personalised therapies. Determination of cytogenetics, molecular and biological characteristics of the disease would be helpful in identifying high-risk features relevant to local population and in advocating risk adapted therapy. With a potentially enlarging cohort of patients, focus needs to be on molecular targeted therapy along with improvements in upfront therapy and reducing treatment-related morbidity.

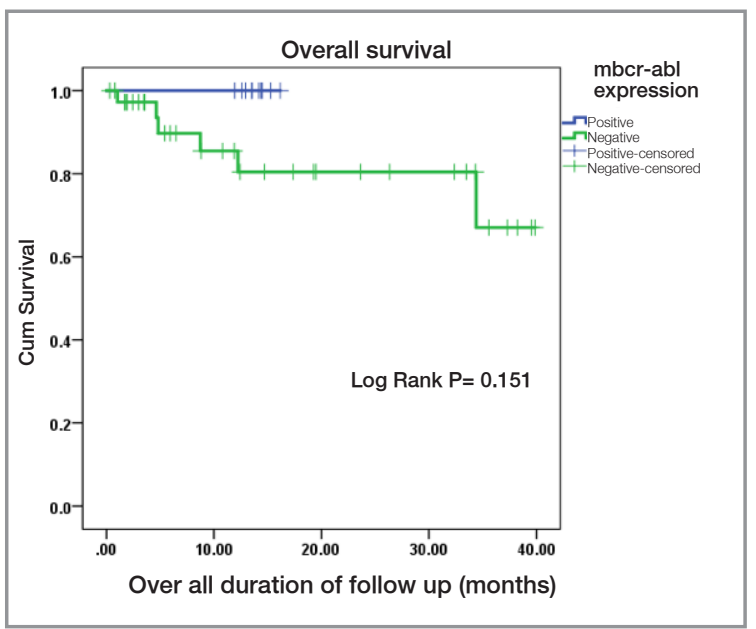

Figure 2. Overall Survival according to Ph chromosome status

\section{Acknowledgements}

We would like to thank Nashwa Medhat, Msc, Bassant Nagdy, Msc \& Mustafa Tarek; Kasr AlAiny molecular oncology department; for their technical efforts, sincere help and interest in our work.

\section{REFERENCES}

1. Shalaby RH, Ashaat NA, El Wahab NA, El-Hamid MA and El Wakeel SH. Bcl-2 expression and chromosomal abnormalities in childhood acute lymphoblastic leukemia. AJCR 3: 3443, 2010.

2. Yenan Li, Dehui Zou, Yaozhong Zhao, et al. Clinical characteristics and outcomes of adults with Philadelphia chromosome positive and/or bcr-abl positive acute lymphoblastic leukemia: a single center study from China. Leuk Lymphoma 51: 488-496, 2010. doi: 10.3109/10428190903370361

3. Thomas DA. Philadelphia chromosome-positive acute lymphocytic leukemia: a new era of challenges. Hematology Am Soc Hematol Educ Program 24: 435-443, 2007.

4. Hasnain Q, Abidi I, Iftikhar M. comparison between philadelphia positive and philadelphia negative adult acute leukemias. Biomedica 24: 31-36, 2008.

5. Vellupillai M, Tan LT, Lau LC, et al. Haematological characteristics, molecular analysis and three year follow up - a single institution study. Ann Acad Med Singapore 29: 159-163, 2000.

6. Preti HA1, O'Brien S, Giralt S, et al. Philadelphia-chromosome-positive adult acute lymphocytic leukemia: characteristics, treatment results, and prognosis in 41 patients. Am J Med 97: 60-65, 1994 
International Journal of Hematology and Oncology

7. Udomsakdi-Auewarakul C, Promsuwicha O, Tocharoentanaphol C, et al. Immunophenotypes and outcome of Philadelphia chromosome-positive and -negative thai adult acute lymphoblastic leukemia. Int J Hematol 78: 337-343, 2003.

8. Jesse Jaso, Deborah A. Thomas, Krista Cunningham, et al. Prognostic significance of immunophenotypic and karyotypic features of Philadelphia positive B-lymphoblastic leukemia in the era of tyrosine kinase inhibitors. Cancer 117: 4009-4017, 2011.

9. Wang J, Shen ZX, Saglio G, et al. Phase 3 study of nilotinib vs imatinib in Chinese patients with newly diagnosed chronic myeloid leukemia in chronic phase: ENESTchina. Blood 125: 2771-2778, 2015.

\section{Correspondence:}

Dr. Hebatallah KASSEM

Cairo University, Faculty of Medicine

Kasr Al-Ainy Centre of Clinical Oncology \& Nuclear Medicine

Department of of Clinical and Chemical Pathology

CAIRO / EGYPT

Tel: (02) 01144829798

e-mail: heba.kasem@hotmail.com 